\title{
Identifying Systemically Important Banks in Pakistan: A Quantile Regression Analysis
}

\author{
Shumaila $Z^{1} b^{1} \&$ Abdul Rashid ${ }^{2}$ \\ 1 Shaheed Zulfikar Ali Bhutto Institute of Science and Technology, Islamabad campus, Islamabad, Pakistan \\ ${ }^{2}$ International Institute of Islamic Economics, International Islamic University, Islamabad, Pakistan \\ Correspondence: Shumaila Zeb, Shaheed Zulfikar Ali Bhutto Institute of Science and Technology, Islamabad \\ campus, Islamabad, Pakistan. E-mail: Shumaila.zeb@gmail.com
}

Received: August 24, 2015

Accepted: October 9, 2015

Online Published: November 25, 2015

doi:10.5539/ijef.v7n12p155

URL: http://dx.doi.org/10.5539/ijef.v7n12p155

\begin{abstract}
The basic purpose of this study is to identify the domestic systemically important banks of Pakistan using an unbalanced panel dataset of 21 commercial banks. The study covers the period 2004-2014. The systemic risk of financial institutions is calculated by using Conditional Value at Risk (CoVaR) approach. Specifically, first, the $\mathrm{VaR}$ and CoVaR are obtained as predicted values of quantile regression of individual and market losses. The state variables included in the analysis are the change in three month yield of treasury bills, the change in slope of yield curve, the inflation rate, monthly market returns, and the equity volatility. The study shows that the state variables have significant impacts on the CoVaR of financial institutions. The domestic systemically commercial banks according to this study are National banks of Pakistan, Allied Bank Ltd, Habib Bank limited, Muslim Commercial Bank and United Bank Limited. The results of the study helps policy makers and regulatory authorities to revise policies and regulation by keeping in mind systemically important banks in the economy to reduce the chances of a financial debacle in future in Pakistan and thus rescuing the economy from financial crises.
\end{abstract}

Keywords: systemic risk, Conditional Value at Risk (CoVaR), Value at Risk (VaR), state variables, quantile regression, banks

\section{Introduction}

\subsection{Background of Study}

Central banks worldwide have made a sincere effort towards stabilizing the financial system, especially after the recent global financial crisis of 2008. The global financial crisis of 2008 was so severe that its effects can be seen and observed even now after passing several years. Several studies have been done to investigate its causes of occurrence and socioeconomic and financial effects. Indeed, financial economists, researchers, and central banks are still actively engaged in addressing its major concerns. One of the major concerns of all the central banks around the globe is the identification, measurement, and protection of Systemically Important Financial Institutions (SIFIs).

It has been reported that the Basel Committee on Banking Supervision (BCBS) of the Bank for International Settlements (BIS) introduced some important reforms in their Basel capital adequacy regime after investigating the main causes of financial crunch of 2008.Such improvements and reforms are commonly referred as Basel III. The BCBS has designed and developed a comprehensive framework of reforms and its associated measures. The major objectives of such reforms and measures are to strengthen and enforce the regulation, continuous monitoring, and risk management of the all the financial institutions mainly focusing on the banking sector. This committee clearly indicated the aims and objective of these measures and reforms which are given below:

- Enable the financial institutions to be more flexible so that they can survive themselves in case of any economic crisis and develop the ability in their operations to cope with the economic pressure, stress, and uncertainly.

- Improving the governance of financial institutions.

- Improving the transpierces of operations of financial institutions.

The new regulations under Basel III framework acquire global capital and liquidity rules (Allahrakha, 
Glasserman and Young, 2015).The underneath intention of the reforms in the Basel III is to make the banking system more robust by addressing the important issues of pro-cyclicality and lessening of systemic risks. The BCBS has approved target ratios and transition periods from 2013 to 2019 during which banks are required to conform to new requirements.

No doubt, the commercial banks play a significant role in the financial and economic system of a nation. The non-stability of the financial system can adversely affect the whole economy of a nation. Therefore, to further improve the effectiveness of a financial system, policymakers, regulators, and academicians always pay a great attention for the reliability and stability of the financial sector (Rodriguez-Moreno, Pena, 2013).

It is apparent from the recent studies that commercial banks contribute significantly in the development of Pakistan. Pakistani banks constitute about 95 percent of the financial sector. As far as the implementation of Basel III in Pakistan is concerned, the State Bank of Pakistan (SBP) has issued strict instructions to Pakistani banks and Development Financial Institutions (DFIs) for its implementations (State Bank Report, 2014). These new instructions incorporate core capital, leverage and capital conservation buffer of the Basel III framework. In the Pakistani perspective, the State Bank of Pakistan has raised the core capital requirements of the banks since 2005. Moreover, in Pakistan, due to nonappearance of hybrid capital instruments, the execution of the Basel III reforms would be moderately easy.

The literature review reveals that significant work has been done towards the management and identification of Global Systemically Important Banks (G-SIBs) (Chouinard \& Ens, 2013). However, still less importance is paid towards the analysis and identification of Domestic Systemically Important Banks (D-SIBs), which is also indispensable. According to the definition of G-SIBs, D-SIBs would have an economically important spillover effect upon their failures, having serious repercussions on the economy and would weaken the whole financial structure, especially within the nation. Central banks consider financial stability as their one of fundamental missions. So it becomes very important to identify and rescue D-SIBs.

Given this context, we argue that serious efforts must be done for D-SIBs as well. However, until now, neither the total number of D-SIBs in Pakistani banking system, nor any official assessment approach has yet been announced in Pakistan. Hence, the domestic systemic risk in the Pakistan banking system as well as its relative distributions among various banks is still unclosed. To the best of our knowledge, no significant study has done for measuring and analyzing domestic systemic risk for Pakistani banking system. Therefore, this study is an attempt to identify domestic systemically important banks in Pakistan using conditional value at Conditional Value at Risk (CoVaR) with the assistance of quantile regression.

\subsection{Contextual Analysis}

The repercussions of great recession of 2007 have initiated the motivation among participants of the markets, regulatory authorities and academicians for the better understanding of systemic risk. A financial firm cannot function properly when its equity value falls sufficiently as compared to outstanding liabilities. Such a firm may be acquired or face bankruptcy which shows that the firm is systemically risky and faces shortfall of capital. This will eventually bring the whole financial sector under stress.

Brownlees and Engle (2011) stated that financial sector is systemically imperative and inability of the firm to fulfill the requirements of customers and creditors would have negative implications for the financial system and the whole economy. The banking industry is an important sector to keep the wheel of economy running. Therefore, there is utmost need of identifying the systemically important banks of Pakistan. This identification definitely helps policy makers and regulatory authorities for an effective management and improvement of banking sector.

\subsection{Significance of the Study}

Before the aperture debate on the rudiments of systemic risk and systemically important financial institutes in an economy, the elementary question arises that what should be the strategy to deal with risks. Whether financial risk should be eradicated completely or efforts must be made to elicited or minimize the risk. In response to answer this question, Lo (2009) stated that to eradicate all the systemic risk is not appropriate and is not admissible as risk is an imperative component for the growth of economy.

Hence, the main focus of the study is not to prevent the financial sector from participating in risky ventures but has the aim to identify, manage and evaluate risks of the whole system along with dealing the risk of individual institutions. The event of recent global financial crisis has enforced us to investigate the deterioration caused by systemic risk and it had serious repercussions for the economies. Hence, it can be argued that it is the public policy concern, not only the issue of financial stability only. 
Significantly, the study is one of the pioneer studies of Pakistan, which is an attempt to identify domestic systemically important banks of Pakistan. This brings into attention to one of the major concerns of economies and gives direction to policy makers and regulatory authorities for mitigating the risk as it has severe impact on the overall economy. This identification would help to eliminate or at least minimize the risk of economic collapse in the future.

\subsection{Problem Statement}

The banking industry is an essential part of the country's financial system. After the recent global financial crisis of 2008, great emphasis is being done to identify systemically important financial institutes to preserve them from entering into a financial crisis. And by some means they enter then how to rescue them. Therefore, there is dire need for a research to identify domestic systemically important banks of Pakistan.

\subsection{Research Objectives}

The main objectives of the study are as follows:

- To identify systemically important banks of Pakistan using quantile regression.

- To suggest policy recommendations based on empirical findings.

\subsection{Research Questions}

This study attempts to answer the following research questions:

- Which are systemically important banks of Pakistan?

- Do changes in three month yield of treasury bills influence CoVaR?

- Does the change in slope of yield curve influence CoVaR?

- Does CoVaR incur any effect from the monthly market returns computed from KSE100 index?

- Does CoVaR have a significant relationship with inflation rate of Pakistan?

- Does CoVaR have a significant relationship with Equity Volatility?

\section{Literature Review}

The literature on systemic risk consists of models that are theoretical that examine the important and significant aspects of systemic risk. Another strand of literature highlighted empirical analyses of historical events considered to be a financial crisis. Extreme efforts are being made by the researchers to elaborate ways to measure, identify and assess systemic risk.

The review of literature reveals that there is not a single integrated and agreed framework or standard that can help to measure the systemic risk. Gaspar (2012) defined systemic risk as a disturbance in the financial system by posing threats and negative repercussions for the financial market and economy. The study further argued that systemic risk has two imperative sources. The first one initiates from borrowings and non financial institutions that give rise to great deal of risk exposure. The second one is called linkage risk that arouse because of enhanced connectivity that paves the way for shocks Various researchers have used different ways to measure systemic risks. Chouinard and Ens (2013) stated that there is advancement in assessing systemic risk quantitatively and can be categorized as market based models and exposure based network models. Market based models used data of high frequency. This depicts that as size is a larger contributor to systemic risk there are other additional contributors whereas exposure based network models based on connectedness among the banks but a drawback is data huge data is required.

Glasserman and Young (2015) analyzed the data set retrieved from the Federal Reserve bank for estimating the systemic importance of the bank holding companies (BHCS) in the USA by making comparison on integratedness, size and activity on the global basis and the analysis revealed the need for managing and monitoring multifarious features of systemic importance. Bullard, Christopher and Wheelock (2009) analyzed that non financial firms posed less systemic risk as compared to financial firms that are systemically more risky. The study suggested the need for reforms for the benefit of economy and thus helps in mitigating systemic risk by creating the ways that can be helpful in rescuing the large financial firms from failures.

Kaserer and Lahmann (2011) measured the systemic risk by expected systemic shortfall (ESS) of the overall financial sector and individual banks by taking the sample of 83 international banks globally and the results revealed that globally 23 banks are systemically important conforming the statement very common "too big to fail". Zhou (2010) highlighted the three measures which are of utmost systemic importance of financial institution within the domain of interlinked and integrated financial system. The empirical as well as theoretical 
evidence depicted that size is not considered as imperative systemic proxy while estimating the systemic risk by single financial institution to the whole financial sector. The results of the study endorsed the fact that too big to fail justification is not always right. As far as identification is concerned it is an easier part and can be doable using certain standard step but measuring is somehow a difficult task to achieve. This seems to be a highly complex problem and according to our view it is a multi dimensional issue. The majority of the literature investigates systemic risk and risk spread outs in banks.

Gravelle (2005) described a vulnerability indicator of corporate sector, the Expected Number of Defaults (END), which is calculated by combining incident of defaults among many firms. The Expected Number of Defaults (END) indicator is wide-ranging that has a potential to analyze the systemic risk enough to assess systemic risk in the financial as well as corporate sector. This indicator is designed using the information about financial securities prices. Data retrieved from balance sheet and the use of equity prices assisted them to compute the Expected Number of Defaults (END) for assessing the systemic risk in the corporate sector of Malaysia, Thailand and Korea (Lu, Stander, \& Yu, 2003). They also discussed how the deficiencies of vulnerability indicators are suppressed by Expected Number of Defaults (END) systemic risk indicator..

Acharya et al. (2010) calculated Systemic Expected Shortfall (SES) and Marginal Expected Shortfall (MES) by using equity returns of financial institutions. When the financial sector lies in the left tail the Marginal Expected Shortfall is middling loss of an institution. The Systemic Expected Shortfall is calculated by its leverage and by calculating the weighted average of the Marginal Expected Shortfall of the institution.

Brownlees and Engle (2011) employed empirical methodology for measuring systemic risk by using non-parametric tail estimators and bivariate GARCH model. Systematic risk captured the shortage of capital and the result indicated that financial system capitalization started deteriorating in the aftermath of global financial crises. Allen et al. (2010) proposed a method of measuring cumulative systemic risk (CATFIN). The CATFIN is different from the other level of systemic risk measures such as Marginal Expected Shortfall and CoVaR. This new measure by considering the banking system as entire anticipated the systemic risk by entailing macroeconomic effects.

Grimaldi (2010) proposed a new financial stress indicator to predict disruptive events with special focus on the Euro area. It is one of the pioneer studies to develop an indicator of financial stress with main prominence on the Euro area. It is also one of the few studies to use the information contained in central bank communication to help in measuring stress in financial markets. The indicator is able to proficiently take out information from an otherwise noisy signal and provide valuable information about the stress level in the markets of the country. They derived a financial stress measure in the form of an indicator (FSI). The study used appropriate threshold levels, which made possible to identify systematically important institutes when markets are in stress. The limitation of this study is explanation of these threshold levels. The study needed to provide the explanation of how to choose these threshold levels. It's impotent in a way that these threshold levels enable to identify systematically important institutes when markets are in pressure.

Huang (2011) propounded indicator of a systemic risk which is calculated by the insurance price against systemic financial suffering. The individual banks role in the systemic risk is evaluated by the indicator. This methodology is applied on the data that is publicly available by taking into consideration 19bank holding companies that are under the umbrella of US Supervisory Capital Assessment Program (SCAP). The study depicted the bank's linear contribution to the systemic risk in probability of default. On the other hand, they also discovered an important association that the contribution to systemic risk is not linear as far as the size of the institution is considered and the assets correlation. It has been found that an increase in systemic risk of the banking sector of US during the time period from 2007 to 2009 financial crunch was primarily driven because of sensitive liquidity and default risk premiums and afterward due to worsening in actual default risk. The study recommended that in finding the importance of each bank's systemic risk contribution size is the main contributor. An important consideration is about the size, which does not change significantly with the passage of time. For example, size does not change much within a quarter. The systemic significance of every financial institution is found by its size, probability of default, and correlation of assets of among institutions in the portfolio.

Schwaab (2011) proposed a moderator framework for estimating financial system risk. On the basis of state space method dynamic factor framework was used by constructing forward looking indicator and coincident measures. For assembling common factors underlying macro-financial and credit risk environment the statistical techniques were employed on a large dataset. For inferring conditions of financial risk 400 European and 450 US financial institutions, and numerous non-financial firms are selected by amalgamating failure counts, 
macroeconomic data, and expected default frequencies They used Mixed Measurement Dynamic Factor Model (MM-DFM) technique is used. Early warning indicators of financial crunch are propounded on the basis of deviations from risk of credit. The analysis is carried out from the time period1984 (Q1) to 2010 (Q4).

The systemic risk measure propounded by Brownlees and Engle (2012) and Acharya, Engle and Richardson (2012) extended the MES. Their methodology comprises the size of the financial institution and the liabilities both. Their study introduced a new methodology for estimating the capital that a financial institution would be in need in the circumstances of another financial crisis. The data that is publicly available is used in this measure and the method resembles with the USA and European regulators stress test. On the basis of crises affecting the whole financial system SRISK relates to the expected capital shortfall of a given financial institution. In this regard, the firms with more shortfall of capital are the greatest contributors for the financial crunch and such institutes fall under the category of most systemically risky institutes (Brunnermeier, Dong, \& Palia, 2012).

Brunnermeier (2008) propounded systemic risk measure that is $\Delta \mathrm{CoVaR}$. An institution being in distress it is calculated as the difference between the conditional values at risk $(\mathrm{CoVaR})$ of the financial system. The CoVaR is dependent on the median state of financial sector. The $\triangle \mathrm{CoVaR}$ estimates stated that features of financial institution such as size, age, leverage, maturity mismatch, and booms in asset price predicts a significant contribution of systemic risk.

Tarashev (2011) developed a measure to calculate systemic risk. It analyzed the way in which a bank transmits the shock in the banking system and its own vulnerability to shocks. The contribution of integrated and connected banks to systemic risk is estimated by this measure. The empirical implementation of the estimate reveals that systemically importance of the bank relies heavily on the bank's role as a lender and borrower in interbank network. The findings elucidate the fact that different approaches lead to different measures of systemic importance. The findings of the study indicate that, prudent regulatory authorities and policy makers should be very tactful in selecting an approach that matches with their concept of systemic importance.

Gray (2013) attempted to re-examine risk transmission in the financial institutions and how it affects financial stability. For measuring systemic solvency risk presented a forward-looking systemic framework Contingent Claims Analysis (CCA) has been put forward. This approach used CCA of advance level for generating estimates of multiple institutions regarding default by using multivariate Extreme Value Theory (EVT) as a conditional tail expectation. The framework paves the way in quantifying the contribution to systemic risk by individuals and contingent liabilities of the financial sector during times of financial stress and crunch.

Cao (2013) propounded a systemic risk measure for capturing the systemic importance of every financial institution efficiently within a given financial system. He stated that when we are talking about the term systemic risk it refers to the contagion risk, and shows the each banks part in the financial system as a whole. The whole process can be divided in two parts: (i) the systemic risk calculation totally, (ii) a rule in quantifying the total risk to each financial institution. For estimating the total systemic risk the study measures "Multi-CoVaR". The institution's marginal contribution to the systemic risk is measured by this estimation given that institution is in distress. To allocate the total systemic risk Shapley value methodology is used.

Girardi (2014) modified Adrian and Brunnermeier's (2011) CoVaR. The definition of financial distress has been changed from an institution being exactly at its value at risk (VaR) to being at most at its VaR. The systemic risk contributions of four financial industry groups comprising of a large number of institutions for the timeline between June 2000 to February 2008 has been used in the study.

For measuring a financial firm's systemic risk, Engle (2015) propounded the SRISK index. The index linked the capital shortfall a financial sector to systemic risk with the expectation to experience condition of a severe market decline. The SRISK is because of various features of institution that include the size of firm, its degree of leverage and its expected equity loss dependent on the downturn and volatility in the market. The sum of SRISK across all the firms measures the degree of undercapitalization of financial sector of the economy as a whole. The study us analyzed the systemic risk of top US financial firms between January 2005 and December 2012.The findings of the study are useful and highlighted that the methodology adopted gives useful rankings of systemically risky firms at various stages of the financial crunch. The study also highlighted the fact that SRISK rankings identify that the great giants in the market such as Fannie Mae, Freddie Mac, Bear Stearns, Morgan Stanley, and Lehman Brothers as the top systemic contributors as early as 2005-Q1. Moreover, the study also elucidates the fact that in pre-crisis SRISK is an important predictor of the capital injection from the Fed during the period of crises and escalation in the systemic risk is a sign of the drop in the products of industries and a rise in the rate of unemployment.

In this study, our main focus is to highlight the domestic systemically important banks of Pakistan. In this study, 
we have used the concept of CoVaR proposed by Adrian and Brunnermeier (2014). The CoVaR is the most suitable methodology because it can be helpful in the identification of systemically important institutions. One of the major drawbacks of CoVaR is that it is not appropriate in aggregating the systemic risk contributions of institutions at individual level. But this methodology fulfills our requirement because in this study, we are most concerned about knowing or highlighting domestic systemically important banks of Pakistan. This study is much beneficial in a way that with the use of CoVaR we can identify domestic systemically important banks of Pakistan.

Manganelli, Kim, and White (2012) propounded a dynamic CoVaR estimation by using a combination of quantile regressions and GARCH. The model proposed in the study is the extension to quantile models from the Value at Risk (VaR) model. Spill over in the VAR is analyzed by using market equity returns. CoVaR is basically $\mathrm{VaR}$ of institution $\mathrm{i}$ conditional on institute $\mathrm{j}$ which is supposed to be in financial distress.

\subsection{Literature Gap}

The global financial crisis of 2008 sheds light on the identification and measurement of systemic risk, which is considered as a major contributor to the global financial crisis of 2008 (Bullard, Neely, \& Wheelock, 2009). The systemic risk is basically a possibility that could generate stern unsteadiness in an entire financial industry and economy of a country. Instead, we can argue that it a kind of phenomena that emerges automatically under routine observations. Furthermore, it is stated that systemic risk is of course not an amendable phenomena, anyways this argument is arguable. The systemic important institutions are very large comparative to their respective industries. Hence, they compose significant part of the on the whole economy. A company that is highly interrelated with others is also a source of systemic risk.

Girardi (2013) used CoVaR to identify systemically important financial institutes of America. There is a dire need to identify domestically important financial institutes or banks of Pakistan as well. This study would make an attempt to identify systemically important banks of Pakistan.

\section{Research Methodology and Data}

\subsection{Data and Sample}

The study has used monthly returns of all listed commercial banks of Pakistan for the time period 2004 to 2014. KSE100 Index is used as a proxy for the financial market for the same time period i-e 2004 to 2014. Data for the state variables which are being used in the study is taken from World Development Indicators (WDI) and International Monetary Fund (IMF). The Stata 12 is used in the study to conduct the analysis. There are 38 scheduled banks operating in Pakistan whereas sample of study comprises of 21 listed commercial banks on the basis of data availability.

\subsection{Empirical Specification of the Model}

We calculated systemic risk of financial institutes using Conditional value at risk (CoVaR) proposed by Adrian and Brunnermeier (2014). The VaR and CoVaR are calculated using predicted values of quantile regression of state variables. One of the common measure of calculating risk faced by financial institutions is Value at risk (VaR). According to many studies like Adrian and Brunnermeier (2014) CoVaR is considered as a better approach to measure the systemic risk contribution in financial institutes of any economy. They define CoVaR as the VaR of institute $i$ which is condition on institution $j$ being in financial distress. The addition of conditional institution helps to capture not only individual risk but also the spillover effect between various financial institutions.

A tail risk metric, CoVaR quantifies the scale of expected losses once the Value at Risk (VaR) breakpoint has been breached. VaR represents a breakpoint that is rarely expected to be surpassed. The CoVaR explores what happens on those occasions when the VaR cutoff is breached. CoVaR is the average of the extreme losses in the "tail" of the distribution. The CoVaR measure can be calculated in a number of ways. But the recent study has taken help from quantile regression because it is one of the easiest and simple ways of calculating CoVaR.

In this study quantile regression is used to compute CoVaR. The quantile regression is a sophisticated form of Ordinary Least Square (OLS). The quantile regression estimates the given set of variables with using conditional median or any other quantile of the response variable. The quantile regression gives a more inclusive depiction of the impact of independent variables on the dependent variable. Instead of estimating the model with OLS linear method, the quantile regression produces different effects along the quantiles of the dependent variable.

\subsubsection{Measuring Losses}

Our analysis is based on the publicly available data. The main focus of the study is on return losses to market 
equity. Specifically, the value of losses of market equity is calculated using the following formula:

$$
X_{t+1}^{i}=-\Delta N_{t+1}^{i} / N_{t}^{i}
$$

We calculated losses based on market equity. However, one can also calculate the return losses using book equity. The book equity is defined as the difference between total assets and total liabilities. Further, the computation of risk measures can be done separately for assets and liabilities.

\subsubsection{Quantile Regression}

The predicted value of a quantile regression of financial sector losses $X_{q}^{\text {system }}$ on losses of an institution i for $q \%$-quantileis given as follow:

$$
\hat{X}_{q}^{\text {system } \mid X^{i}}=\hat{\alpha}_{q}^{i}+\hat{\beta}_{q}^{i} X^{i}
$$

where $\hat{X}_{q}^{\text {system } \mid X^{i}}$ denotes the predicted value for a $q \%$-quantile of the system conditional on a return realization $X^{i}$ of institution $i$.

According to the definition of value at risk, we can rewrite it as follows:

$$
\operatorname{CoVaR} R^{\text {system } \mid X^{i}}=\hat{X}_{q}^{\text {system } \mid X^{i}}
$$

It is obvious from the above equation that predicted value from the quantile regression of system return losses on the losses institution $i$ gives the value at risk of the financial system conditional on $X^{i}$.

The $\operatorname{CoVaR} R^{\text {system|i }}$ given $X^{i}$ is just the conditional quantile. Using the particular predicted value of $X^{i}=\operatorname{VaR} R_{q}^{i}$ yields the required $\operatorname{CoVaR} R_{q}^{i}$ measure, that is, $\operatorname{CoVaR}_{q}^{\text {system } \mid X^{i}=\operatorname{VaR}_{q}^{i}}$.More specifically, according the quantile regression framework, the specific $\mathrm{CoVaR}_{q}^{i}$ measure can be expressed as follows

$$
\operatorname{CoVaR}_{q}^{\text {system } \mid X^{i}=\operatorname{VaR}}{ }_{q}^{i}=\hat{\alpha}_{q}^{i}+\hat{\beta}_{q}^{i} \operatorname{VaR}^{i}
$$

\subsubsection{VaR, CoVaR, and Systematic State Variables}

In this study, in order to capture the time variation in joint distribution of $X^{\text {system }}$ and $X^{i}$, we estimate VaRs and CoVaRs as a function of state variables. This estimation has allowed us to model the evolution of the conditional distributions over time. We indicate time-varying $\operatorname{CoVaR}_{q, t}^{i}$ and $V a R_{q, t}^{i}$ with a subscript $t$ and estimate the time variation conditional on a vector of lagged state variables $M_{t-1}$. We run the following quantile regressions in the monthly data (where $i$ is an institution).

$$
\begin{gathered}
X_{t}^{i}=\alpha_{q}^{i}+\delta_{q}^{i} M_{t-1}+\varepsilon_{q, t}^{i} \\
X_{t}^{\text {system } \mid i}=\alpha_{q}^{\text {system } \mid i}+\delta_{q}^{\text {system } \mid i} M_{t-1}+\gamma_{q}^{\text {system } \mid i} X_{t}^{i}+\varepsilon_{q, t}^{\text {system } \mid i}
\end{gathered}
$$

Finally, to obtain the $\operatorname{VaR} R_{q, t}^{i}$ and $\operatorname{CoVaR} R_{q, t}^{i}$, we generate the predicted values from equation (5) and (6) as follows.

$$
\begin{aligned}
\operatorname{VaR} R_{q, t}^{i} & =\hat{\alpha}_{q}^{i}+\hat{\delta}_{q}^{i} M_{t-1} \\
\operatorname{CoVaR} & \hat{\alpha}_{q, t}^{\text {system } \mid i}+\hat{\delta}_{q}^{\text {system } \mid i} M_{t-1}+\hat{\gamma}_{q}^{\text {system } \mid i} V a R_{q, t}^{i}
\end{aligned}
$$

\subsubsection{State Variables}

The state variables which are being used in this study have two distinct features. Firstly, they very well capture time variation in certain conditions and secondly they are liquid. The lags of systemic state variables are used in estimations. These state variables should not be treated as systemic risk factors they are rather considered as conditional variables in the study. It is important to mention that theses state variables might have different effect 
on different commercial banks of Pakistan. In order to keep the data manageable the study is restricted to a small set of risk factors.

The risk factors which are used in the study are as follows:

i. The change in three month yield from State Bank of Pakistan.

This study has used change in three month Treasury bill rate. In this study we are more interested in the change rather than the level because change is most significant in explaining the tails of financial sector market valued asset returns.

ii. The monthly market return computed from KSE100 index.

iii. The change in the slope of the yield curve. In the recent study we have calculated this measure by taking the yield spread between the long term bond and Treasury bill rate obtained from the State Bank of Pakistan.

iv. The inflation rate. In the study we have taken Consumer Price Index is taken as a proxy for the inflation rate of Pakistan.

v. Equity volatility is calculated as the 22 day rolling standard deviation of the monthly KSE100 index equity market return.

\subsection{Hypotheses}

The proposed hypotheses of the study are listed below:
$\mathrm{H}_{1}$ : CoVaR has a positive significant relationship with change in three month yield of treasury bills.
$\mathrm{H}_{2}$ : CoVaR has a positive significant relationship with change in slope of the yield curve.
$\mathrm{H}_{3}$ : CoVaR has a significant relationship with the monthly market returns computed from KSE100 index.
$\mathrm{H}_{4}$ : CoVaR has a significant relationship with price levels.
$\mathrm{H}_{5}$ : CoVaR has a significant relationship with equity volatility.

\section{Empirical Results and Discussions}

Depending upon the structure of each economy, a sound and stable financial system is essential for its continual success and development through the best performance in the banking sector. The previous literature reveals that in each economy central bank is responsible for implementing the financial regulations over a period of time on the commercial banks with an aim to improve their functionality in every possible way. The most important function of these financial regulations is to safeguard commercial banks from any possible financial crisis and to rescue them if commercial banks by some means have entered in to financial crisis. The systemic risk is one of the major factors which might be involved in bringing commercial banks in financial crisis. Great efforts are being made by different countries of the world to minimize the systemic risk faced by the financial institutions.

In this study, we have calculated CoVaR of commercial banks of Pakistan using quantile regression. The main purpose of using quantile regression is that it is one of the easiest ways of computing CoVaR. This study has provided empirical evidence that either state variable which are being used by the study, influence the systemic risk of commercial banks or not. The unbalances panel has been used in the study for the time period 2004 to 2014 .

\subsection{Descriptive Statistics}

Descriptive statistics provide the useful insight of the data. It generally talks about the general trend of sate taken in the study. The descriptive statistics highlight number of observations, mean, standard deviation, minimum and maximum. The descriptive statistics of state variables and individual bank losses and financial system losses are provided in Table 1.

Table 1. Descriptive statistics of state variables variables

\begin{tabular}{llccl}
\hline & Mean & Std.Dev & Min & Max \\
\hline Xsystem & 0.0149 & 0.0743 & -0.4487 & 0.2023 \\
Xi & 0.0064 & 0.1559 & -0.2000 & 2.5800 \\
yield & 0.0590 & 0.4220 & -1.4100 & 1.5800 \\
yieldcurve & -2.5700 & 5.6600 & -14.0100 & 2.7800 \\
cpi & 91.23 & 31.1800 & 48.6300 & 144.9800 \\
rv & 0.0650 & 0.0290 & 0.0230 & 0.1560 \\
\hline
\end{tabular}


Table 1 shows the important descriptive statistics of all the state variables used in the study. According to Table 1 the mean value of yield is found to be 0.059 , cpi, which is used as proxy of price levels in Pakistan is found to be 91.23. Similarly, the rolling volatility which is represented by rv has a mean value of 0.065 . The standard deviation of rolling volatility rv is found to be as low as 2.3 percent.

Table 2. Descriptive statistics of CoVaR and VaR

\begin{tabular}{lcccc}
\hline & Mean & Std.Dev & Min & Max \\
Var & 0.0220 & 0.0210 & -0.1160 & 0.3784 \\
CoVaR & -0.0011 & 0.0080 & -0.0167 & 0.0277 \\
\hline
\end{tabular}

Table 2 presents the descriptive statistics of $\mathrm{VaR}$ and CoVaR computed in the study using predicted values of quantile regressions. The mean value of $\mathrm{VaR}$ is found to be 0.0220 having standard deviation of $2.1 \%$. The minimum of $\mathrm{VaR}$ is -0.1160 while maximum is 0.3784 . The mean value of CoVaR is found to be -0.0011 having a standard deviation of almost 0.008 for the commercial banks of Pakistan.

\subsection{Correlation Matrix}

In this study we have employed five state variables, losses of individual commercial banks, losses of the financial system. We then calculated $\mathrm{VaR}$ and $\mathrm{CoVaR}$ of commercial banks of Pakistan using quantile regression. Table 3 given the correlation details of all the state variables used in the study.

Table 3. Intercorrelation among the variables

\begin{tabular}{|c|c|c|c|c|c|}
\hline Xsystem & $\mathrm{Xi}$ & Yield & Yield curve & cpi & \\
\hline $\mathrm{Xi}$ & $0.3595^{*}$ & - & & & \\
\hline Yield & $-0.3700^{*}$ & -0.0030 & - & & \\
\hline Yield curve & $0.4150^{*}$ & 0.1020 & -0.0440 & - & \\
\hline cpi & $-0.7480 *$ & 0.0610 & -0.2130 & 0.1910 & - \\
\hline rv & -0.0160 & -0.0020 & 0.0090 & $-0.2890 *$ & -0.4250 \\
\hline
\end{tabular}

Note. $* \mathrm{P}<0.05$.

Table 3 the correlation matrix of all the state variables used in the study. It is obvious from the table that almost all the variables have a strong correlation with each other. Inflation within the Pakistan is highly correlated with the losses of the financial system having a strong correlation of 0.085 . The yieldcurve is also highly correlated with the losses of financial system having a correlation of 0.4150 . The losses in individual financial institute are also highly correlated with the losses of the whole financial system having a strong value of 0.3595.

\subsection{Regression Analysis}

Table 4 describes about the financial losses of the financial system on individual financial institutes particularly commercial banks. The above table clearly depicts the picture that financial losses of individual commercial banks have positive significant effect on the financial losses of financial system. The coefficient value is 13.8 which means that per unit change in financial losses of individual commercial banks on the whole causes 13.8 percent change in financial losses of financial system. The t-statistics is 20.2 and significant at 0 percent. The predicted value of this regression are actually the q percent quantile of the financial system condition on a return realization of individual institution $\mathrm{i}$. From the universal definition of VaR, the predicted values obtained in this regression is $\mathrm{CoVaR}=\mathrm{Xqsystem}$.

Table 4. Financial sector losses on the losses of particular institutions

\begin{tabular}{|c|c|c|c|c|}
\hline \multicolumn{5}{|c|}{ Dependent Variable: Xsystem } \\
\hline Variable & Coefficient & Std.err & t-statistics & Prob. \\
\hline$X i$ & 0.138 & 0.006 & 23.000 & $0.000^{*}$ \\
\hline Constant & 0.020 & 0.001 & 19.50 & $0.000 *$ \\
\hline R-square & 0.670 & & & \\
\hline
\end{tabular}

Note. $* \mathrm{P}<0.05$ 
Table 5 presents the results on the relationship between individual financial institutions on the lag of all the state variables used in the study. The quantile regression is used on the monthly data. This table explains that lag of all the state variables are found to be positively significant except rolling volatility rv. The rv is actually computed as 22 day rolling standard deviation of monthly market return. The lag of variable yield is found to be significant at 10 percent level of significance while lags of yield curve and cpi are found to be statistically significant at 5 percent level of significance.

Table 5. Results for state variables on individual financial institutions

\begin{tabular}{lllll}
\hline Dependent Variable : Xi & \multicolumn{4}{c}{} \\
\cline { 2 - 5 } Variables & Coefficient & Std.Err & t-stat & Prob \\
\hline Yield & 0.006 & 0.003 & 1.720 & 0.086 \\
Yieldcurve & 0.109 & 0.020 & 5.450 & $0.000^{*}$ \\
cpi & 0.117 & 0.051 & 2.294 & $0.001^{*}$ \\
Rv & 0.233 & 0.054 & 4.314 & $0.003^{*}$ \\
Constant & -0.032 & 0.008 & -3.83 & 0.000 \\
R-square & 0.604 & & & \\
\hline
\end{tabular}

Note. $* \mathrm{P}<0.05$.

Table 6. Results state variables on financial system

\begin{tabular}{lllll}
\hline Dependent Variable:Xsystem & & & & \\
\hline Independent Variables & Coefficient & Std.Err & t-stat & Prob \\
\hline cpi & 0.102 & 0.005 & 20.40 & $0.030^{*}$ \\
Yield & -0.032 & 0.003 & -10.66 & $0.043^{*}$ \\
Yieldcurve & 0.041 & 0.020 & 2.050 & $0.040^{*}$ \\
rv & 0.040 & 0.045 & 0.888 & 0.36 \\
Mrind & 0.133 & 0.008 & 16.625 & $0.000^{*}$ \\
Constant & 0.008 & 0.007 & 1.142 & 0.22 \\
R-square & 0.67 & & & \\
\hline
\end{tabular}

Note. $* \mathrm{P}<0.05$.

Table 6 presents the estimates on the relationship between financial system and lags of state variables and individual financial institutes. According to the above table lag of cpi, which is used as a proxy of inflation is found to be positively significant with financial system. The $t$ stat for cpi is found to be 2.16 . The coefficient is found to be 0.102 which means per unit increase in cpi would raise Xsystem by 0.102 . The lag of yield curve is also found to be positively significant with Xsystem. The t stat of lag of yieldcurve is 2.04 while $\mathrm{p}$ is found to be significant at 5 percent. The rv is found to insignificant with Xsystem.In this study we mostly are concerned with the predicted values of quantile regression. After these estimations of quantile regression we obtained predicted values to obtain $\mathrm{VaR}$ and CoVaR required for the study.

Table 7. Results for $\mathrm{VaR}$

\begin{tabular}{lcccc}
\hline Dependent Variable:VaR & & & & \\
\hline Independent Variables & Coefficient & Std.Err & t-stat & Prob \\
\hline cpi & 0.024 & 0.008 & 3.23 & $0.001^{*}$ \\
Yield & 0.085 & 0.041 & 2.125 & $0.036^{*}$ \\
Yieldcurve & 0.019 & 0.003 & 6.33 & $0.000^{*}$ \\
rv & 0.032 & 0.007 & 4.57 & $0.020^{*}$ \\
Constant & 0.016 & 0.001 & 14.30 & $0.011^{*}$ \\
R-square & 0.634 & & & \\
\hline
\end{tabular}

Note. $* \mathrm{P}<0.05$.

Table 7 displays the results on the relationship between VaR and lag of all the state variables employed in the study. 
According to the above table $\mathrm{VaR}$ is found to be positively significant with all the state variables used in the current study. The cpi has t-stat of 3.23 having probability of 0.001 .

Table 8. CoVaR on lag of state variables

\begin{tabular}{lcccc}
\hline Dependent Variable:CoVaR & & & & \\
\hline Variables & Coefficient & Std.Err & t-stat & Prob \\
\hline cpi & 0.018 & 0.008 & 2.25 & $0.00^{*}$ \\
Yield & -0.024 & 0.004 & -6.07 & $0.00^{*}$ \\
Yieldcurve & 0.054 & 0.003 & 18.15 & $0.02^{*}$ \\
VaR & 0.032 & 0.011 & 3.29 & $0.00^{*}$ \\
rv & 0.0721 & 0.007 & 10.3 & $0.00^{*}$ \\
Constant & 0.004 & 0.001 & 3.74 & $0.002^{*}$ \\
R-square & 0.678 & & & \\
\hline
\end{tabular}

Note. $* \mathrm{P}<0.05$.

Table 8 presents the results for $\mathrm{CoVaR}$ as function of state variables and $\mathrm{VaR}$. The results clearly reveal that $\mathrm{CoVaR}$ of financial institutions surely depends upon all the state variables used in the study as well as on the VaR of financial institutions as well. To know the contribution of state variables in CoVaR it is very important to consider $\mathrm{VaR}$ as well. $\mathrm{CoVaR}$ has an element of spillover effect which is one of the important aspects of the current study. These estimations show that lag of state variables significantly affect the CoVaR. CoVaR is an extension of $\mathrm{VaR}$ that means $\mathrm{VaR}$ of institution $i$ condition on institution $\mathrm{j}$ which is in financial distress.

These above estimations are being done on the unbalanced panel of all the listed commercial banks of Pakistan to know that impact of few state variables on the CoVaR of all the sample selected commercial banks of Pakistan. Theses all estimations are also repeated on single cross section as well to know the impact of each individual commercial bank's CoVaR by the change in the lag of all the state variables being employed in the study. Each cross section has come up with the different results. Out of 21 listed commercial banks being used in the study only few banks have resulted in a higher CoVaR. The results of individual cross section's estimation suggest that all the listed commercial banks can be divided in to two groups. One group is those listed commercial banks which contributes a lot in the systemic risk contribution of the Pakistan. Those important commercial banks according to this study are National banks of Pakistan, Allied Bank Ltd, Habib Bank limited, Muslim Commercial Bank and United Bank Limited. The other group of commercial banks does not significantly contribute towards the systemic risk of the country. The listed commercial banks which are not major contributor of systemic risk towards the economy are commercial banks like Askari bank, Faisal bank, Silk bank, NIB and bank of Khyber.

\section{Conclusion and Policy Implications}

This study is an attempt to empirically identify the domestic systemically important commercial banks of Pakistan. Pakistan is a developing country. The commercial banks of Pakistan constitute about $95 \%$ of its whole financial sector. Therefore it is very important to identify domestic systemically important institutes as it would help policy makers to revise policies and regulation keeping in mind systemically important banks in the economy to reduce the chances of a financial crisis in future in Pakistan in order to safe guard the economy from any future crisis. The importance of financial system cannot be negated for the growth of economy, prosperity and development. The global financial crises are the eye opener for policy makers that are ignored in the past. Therefore the recognition of the systemically imperative financial institutes is a very pivotal step by the regulatory authorities in preventing financial distress. Such steps will be helpful in effective policy formulation and rescue the economy from negative shocks.

The recent study has used quantile regression to calculate VaR and CoVaR of listed commercial banks of Pakistan. A total of 21 listed commercial banks of Pakistan are used in the empirical analysis. The study covers the period of 2004 to 2014. The state variables which are estimated against $\mathrm{VaR}$ and CoVaR are change in three month yield of treasury bills, change in slope of yield curve, inflation rate, and monthly market return and equity volatility. The study concludes that the state variables employed in the study have significant impact on the CoVaR of financial institutions. The cross sectional analysis reveals that National Bank, Allied Bank, United bank and Muslim Commercial Banks are the major contributors of system risk in the economy of Pakistan.

After estimating CoVaR of financial institutions with state variables it is highly recommended to estimate the $\mathrm{CoVaR}$ against financial institutions characteristics as well to further verify the results of the recent study. The 
individual financial characteristics might be size, maturity mismatch, lack of substitutes, liquidity and leverage which the pillars are provided by the Basel Committee of Banking supervision for the identification of global systemically important financial institutions. Some other financial characteristic which might affect CoVaR can also be introduced in addition with the financial characteristics provided by Basel Committee of Banking Supervision.

The procedure of identification of domestic systemically important financial institutions mainly relies on the fact that how the failure or distress of a commercial banks or financial institute will have on domestic economy. In comparison with global systemically important financial institutions or commercial banks, domestic systemically important financial institutes are solely rely on the estimations performed by the countrywide authorities. These countrywide authorities can best judge the impact of failure or distress of a commercial bank or financial institution on local financial system and the overall economy of a country. The standards develop by Basel Committee of Banking supervision for Domestic systemically important financial institutions give national discretion in identifying them. It is on the discretion of the country to identify domestic systemically important commercial banks and financial institutions by keeping in mind all the important principles and indicators given by Basel Committee.

The empirical findings of the study highlighted that in Pakistan National bank, United Bank. Allied Bank, Muslim Commercial bank and Habib bank Limited are contributing towards the systemic risk of Pakistan. The results clearly depict the information that smaller banks contribute less towards systemic risk. The State Bank of Pakistan must devise a framework which could be as provided by the current study to identify domestically important financial institutions for the domestic financial market. These important financial institutes must have higher capital requirements than their peers to prevent the financial system of Pakistan from collapsing in future if there is a presence of financial crisis.

\section{References}

Acharya, V., Engle, R., \& Richardson, M. (2012). A new approach toranking and regulating systemic risks. The American Economic Review, 102(3), 59-64. http://dx.doi.org/10.1257/aer.102.3.59

Acharya, V., Pedersen, L., Philippon, T., \& Richardson, M. (2010). Measuring Systemic Risk. NYU Working Paper. http://dx.doi.org/10.1002/9781118258231.ch4

Adrian, T., \& Boyarchenko, N. (2012). Intermediary Leverage Cycles and Financial Stability. FRB of New York Staff Report. http://dx.doi.org/10.2139/ssrn.2133385

Allahrakha, M., Glasserman, P., \& Young, H. P. (2015). Systemic Importance Indicators for 33 US Bank Holding Companies: An Overview of Recent Data (No. 15-01). Office of Financial Research, US Department of the Treasury.

Bernardi, M., Gayraud, G., \& Petrella, L. (2013). Bayesian inference for CoVaR.

Bernardi, M., Maruotti, A., \& Petrella, L. (2013). Multivariate Markov-Switching models and tail risk interdependence.

Billio, M., Getmansky, M., Lo, A., \& Pelizzon, L. (2010). Measuring Systemic Risk in the Finance and Insurance Sectors. MIT Working Paper.

Brownlees, C., \& Engle, R. (2010). Volatility, Correlation and Tails for Systemic Risk Measurement. NYU Working Paper.

Brunermier, K. M., Dond, G., \& Palia, D. (2012). Banks non interest income and systemic risk. http://dx.doi.org/10.2139/ssrn.1786738

Brunnermeier, M. K. (2009). Deciphering the Liquidity and Credit Crunch 2007-08. Journal of Economic Perspectives, 23(1), 77-100. http://dx.doi.org/10.1257/jep.23.1.77

Brunnermeier, M. K., \& Pedersen, L. H. (2009). Market Liquidity and Funding Liquidity. Review of Financial Studies, 22, 220-2238. http://dx.doi.org/10.1093/rfs/hhn098

Bullard, J., Neely, J. D., \& Wheelock, C. D. (2009). Systemic Risk and the Financial Crisis: A Primer. Federal Reserve Bank of St. Louis Review, 5(1), 403-4017.

Cao, Z. (2013). Multi-CoVaR and Shapley Value: A Systemic Risk Measure. Bank of France Working Paper.

Castro, C., \& Ferrari, S. (2014). Measuring and testing for the systemically important financial institutions. Journal of Empirical Finance, 25, 1-14. http://dx.doi.org/10.1016/j.jempfin.2013.10.009 
Chan-Lau, J. A., \& Gravelle, T. (2005). The END: A new indicator of financial and nonfinancial corporate sector vulnerability.

Engle, R. F., \& Manganelli, S. (2004). CAViaR: Conditional Autoregressive Value at Riskby Regression $\begin{array}{lllll}\text { Quantiles. Journal of Business and Economic Statistics, } & \text { 23(4). }\end{array}$ http://dx.doi.org/10.1198/073500104000000370

Girardi, G. (2013). Systemic risk measurement: Multivariate GARCH estimation of CoVaR. Journal of Banking \& Finance, 37(8), 3169-3180. http://dx.doi.org/10.1016/j.jbankfin.2013.02.027

Hollo, D., Kremer, M., \& Lo Duca, M. (2012). CISS-a composite indicator of systemic stress in the financial system.

Kim, B., \& Giesecke, K. (2011). Systemic Risk: What Defaults Are Telling Us. Working Paper, Stanford University.

Lehar, A. (2005). Measuring systemic risk: A risk management approach. Journal of Banking and Finance, 29(10), 2577-2603. http://dx.doi.org/10.1016/j.jbankfin.2004.09.007

Lu, Z., Stander, J., \& Yu, K. (2011). Quantile regression: Applications and current research area. The Statistician, 331-350.

Oh, D. H., \& Patton, A. J. (2013).Time-varying systemic risk: Evidence from a dynamiccopula model of cds spreads. Duke University Working Paper. http://dx.doi.org/10.2139/ssrn.2269405

Report on the performance financial sector of Pakiststan. (2013). Retrieved from http://www.sbp.org.pk

Schwaab, B., Koopman, S. J., \& Lucas, A. (2011). Systemic risk diagnostics, coincident indicators and early warning signals. Technical report.

Tarashev, N., \& Zhu, H. (2011). Specification and calibration errors in measures of portfolio credit risk: The case of the ASRF model. International Journal of Central Banking ,4, 129-174.

White, H., Kim, T. H., \& Manganelli, S. (2010). VAR for VaR: Measuring systemic risk using multivariate regression quantiles.

\section{Copyrights}

Copyright for this article is retained by the author(s), with first publication rights granted to the journal.

This is an open-access article distributed under the terms and conditions of the Creative Commons Attribution license (http://creativecommons.org/licenses/by/3.0/). 